\title{
Demonstration of the Kamin effect after one-trial avoidance learning'
}

In two experiments, groups of rats were trained to make a one-trial avoidance response, and were given a test of retention at various intervals afterward. The result in both experiments was a ll-shaped retention function (Kamin effect). Because of the nature of one-trial avoidance learning, the Kamin effect does not seem attributable to warm-up factors or to a temporary state of overarousal.

Kamin (1957) found a $U$-shaped retention function with its lower extremum 1 hr. after initial shuttle-box training. Kamin's methods and results have since been replicated by Brush, Myer, \& Palmer (1963), Denny (1958), Denny \& Ditchman (1962), Denny \& Thomas (1960), and Kamin (1963).

Because the Kamin effect has been demonstrated only after shuttle-box training, the initial decline of performance on relearning trials can be attributed to an increase in fear, resulting in freezing behavior, or to a decrease in fear, resulting in less motivation. In addition, it is difficult to separate the effects of fear and warm-up during shuttle-box relearning trials. The following two experiments demonstrate a Kamin effect after one-trial avoidance learning, and thus provide a solution to these problems.

\section{Procedure}

\section{EXPERIMENT 1}

Eighteen, experimentally naive, male, black-hooded rats were trained in a Skinner box to press for continuous water reinforcement. On the avoidance training day, Ss received a .01 sec., 5 ma shock (calibration resistance $=100 \mathrm{~K}$ ) and were immediately removed from

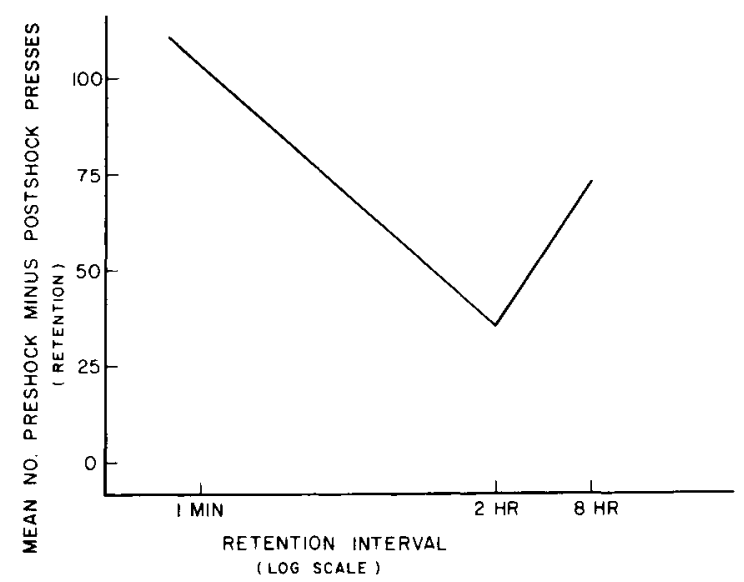

Fig. 1. Percent loss of pressing rate from preshock to postshock trials at different retention intervals. the box. Shock occurred on the firstbar press after $S$ had been in the box for 20 sec. Three groups of six Ss each were tested for retention 1 min., $2 \mathrm{hr}$., or $8 \mathrm{hr}$. after the shock. Training and testing were carried out so that all Ss were deprived of water for $23 \mathrm{hr}$. prior to the last preshock training trial and to the postshock test of retention.

\section{Results}

The measure of retention was the number of presses during the last 10-min. preshock training trial minus the number of presses on the $10-\mathrm{min}$. test of retention. The mean difference scores plotted in Fig. 1 resulted in a significant $U$-shaped function $(F=5.36, p<.05)$. The 1-min. group retained better than each of the other two groups $(p<.05)$, and the $8-\mathrm{hr}$. group retained better than the 2-hr. group $(p<.05)$ 。

\section{Procedure}

\section{EXPERIMENT 2}

Experiment 2 was similar to Experiment 1 except for the following differences. The $25 \mathrm{Ss}$ were trained to drink from a spout. Water was not contingent on a bar press; however, the spout was located just above a large bar which was invariably depressed when Ss drank. Possible shock duration was lengthened to $.1 \mathrm{sec}$. Three groups of five Ss each were returned to the box at the same intervals as used in Experiment 1, but an additional $10 \mathrm{Ss}$ were tested $25 \mathrm{hr}$. following the shock.

Results

As demonstrated by Fig. 2, the 1-min., 8-hr., and 25-hr. groups all spent less time at the spout during the first $5 \mathrm{~min}$. of the test of retention than the 2-hr.

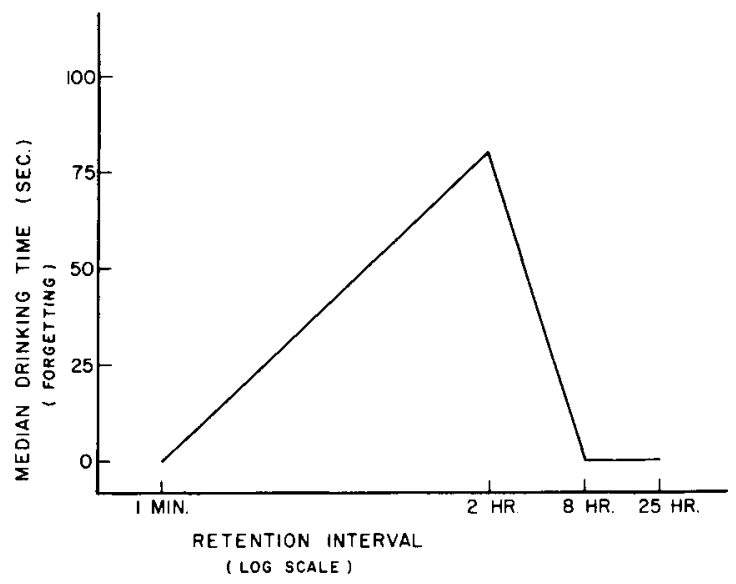

Fig. 2. Time spent drinking during the first 5 min. of the retention test for different acquisition-retention intervals. 
group $(U=2, U=2, U=8, p<.05), U$ tests were used to evaluate these differences since many of the Ss did not drink during the retention test.

\section{DISCUSSION}

In the one-trial avoidance situation, a decrease in fear invariably results in more responding and consequently in poorer shock retention. This is the case irrespective of whether the decrease in fear results in less motivation to avoid or in less freezing behavior. Therefore, since a U-shaped retention function was demonstrated after one-trial avoidance learning, it may be concluded that the lower extremum of the Kamin effect is related to a decrease in fear. If the Kamin effect were due to an increase in fear, retention would have been best rather than worst at $2 \mathrm{hr}$.

Since Ss were removed from the box immediately after being shocked, their avoidance training prior to the test of retention consisted of just one escape response. Since no prior avoidance response had been made, no warm-up factors could have affected avoidance performance on the test of retention. In Experiments 1 and 2 , the Kamin effect was, thus, demonstrated without any effects of warm-up. This supports Kamin's 1963 finding that a monotonic warm-up decrement is not necessary in the production of a U-shaped retention function.

Cooper \& Koppenaal (1964) showed that when onetrial avoidance training directly preceded a single electroconvulsive shock (ECS), there seemed to be little retention of the avoidance training $1 \mathrm{hr}$. later but good retention $24 \mathrm{hr}$. later. They concluded that an ECS only temporarily suppressed the avoidance habit, thus casting doubt on the consolidation interpretation of the effects of ECS. The consolidation theory implies a permanent impairment in retention. However, their experi- mental design was not sensitive to performance changes in the controls, and in the light of Experiments 1 and 2 it is possible that the apparent recovery from ECS suppression reflects an increase in the strength of the avoidance habit from 1 to $24 \mathrm{hr}$. Supporting this view is the fact that in one of the Cooper and Koppenaal experiments the 24-hr. controls showed a slight but consistent tendency to retain better than their respective 1-hr. controls.

This criticism of Cooper and Koppenaal may have significance in a larger context since the one-trial avoidance task is used widely in ECS research. Until more is known about the retention function after onetrial avoidance learning, the present difficulties that seem to exist in the interpretation of the effects of ECS on this function may continue to increase.

\section{References}

Brush, F. R., Myer, J. S., \& Palmer, M. E. The effects of kind of prior training and intersession interval upon subsequent avoidance learning. J. comp. physiol. Psychol., 1963, 56, 539-545.

Cooper, R. M., \& Koppenaal, R. J. Suppression and recovery of a one-trial avoidance response after a single ECS. Psychon. Sci. 1964, 1, 303-304.

Denny, M. R. The "Kamin effect" in avoidance conditioning. Amer Psychol., 1958, 13, 419, (Abstract)

Denny, M. R, \& Ditchman, R. E. The locus of maximal "Kamin effect" in rats. J. comp. physiol. Psychol., 1962, 55, 1069-1070.

Denny, M. R., \& Thomas, J. O. Avoidance learning and relearning as a function of shuttle box dimensions. Science, 1960, 132, 620-621.

Kamin, L. J. The retention of an incompletely learned avoidance response. J. comp. physiol. Psychol., 1957. 50, 457-460.

Kamin, L. J. The retention of an incompletely learned avoidance response: some further analysis. J. comp. physiol. Psychol., $1963,56,713-718$.

\section{Notes}

1. Supported by Canadian N.R.C. grant no. APA-135.

2. Holder of a Canadian N.R.C. bursary. 